\title{
Discovering Spotify - A Thematic Introduction ${ }^{i}$
}

\author{
By Rasmus Fleischer \& Pelle Snickars
}

With a user base now officially reaching more than 100 million, which includes 60 million paying subscribers, the music streaming platform Spotify is today widely recognized as the solution to problems caused by recent decades of digital disruption within the music and media industries. Spotify resembles Netflix, YouTube, and Apple Music as an epitome of streaming's digital Zeitgeist that is shaping our future. Industry interviews, trade papers, academic books, and the daily press reiterate numerous versions of this "technological solutionism" (Morozov 2013) in almost as many variations.

This thematic section of Culture Unbound is broadly concerned with the music service Spotify, and novel ways to situate and do academic research around streaming media. Approached through various forms of digital methods, Spotify serves as the object of study. The four articles presented here-three full length research articles and a shorter reflection-emanates from the cross-disciplinary research project "Streaming Heritage: Following Files in Digital Music Distribution". It was initially conceived at the National Library of Sweden (hence the heritage connection), but the project has predominantly been located at the Umeå University's digital humanities hub, Humlab, where the research group has continuously worked with the lab's programmers. The project involves four researchers and one PhD student and is funded by the Swedish Research Council between 2014 and 2018.ii

While most previous scholarship on Spotify has primarily focused on its service role within the music industry, its alterations to the digital music economy, or its influence on ending music piracy (Wikström 2013, Wikström \& DeFilippi 2016, Allen Anderson 2015, Galuszka 2015, Andersson Schwarz 2013), our

Fleischer, Rasmus \& Pelle Snickars: "Discovering Spotify—A Thematic Introduction", Culture Unbound, Volume 9, issue 2, 2017: 130-145. Published by Linköping University Electronic Press: http://www.cultureunbound.ep.liu.se 
project mainly takes a software studies and digital humanities approach towards streaming media. The project "Streaming Heritage" broadly engages in reverse engineering Spotify's algorithms, aggregation procedures, metadata, and valuation strategies to study platform logics, including underlying norms and structures. Reverse engineering starts with the final product (in our case the music service Spotify) and tries to take it apart, backwards, step-by-step. Basically, we draw a more holistic picture by using Spotify as a lens to explore social, technical, and economic processes associated with digital media distribution. The key research idea within our project is to follow files (rather than the people making, using, or collecting them) on their distributive journey through the streaming ecosystem, taking empirical advantage of inherent data flows at media platforms (such as Spotify).

Over the last ten years, the extensive field of media and Internet studies have used several digital methods to develop pioneering ways to analyse and understand the digital, the Internet, as well as digital media production, distribution, and consumption. Following the catchphrase "the system is the method" (Bruhn Jensen 2011), digital methodologies are increasingly deployed to perform social science or humanistic inquiries on, for example, big data and black-boxed media platforms (such as Spotify) (Ruppert, Law \& Savage 2013). As a research practice, digital methods "strive to follow the evolving methods of the medium" (Rogers 2013:1). The issue of data of, about, and around the Internet, as Klaus Bruhn Jensen has eloquently stated, "highlights the common distinction between research evidence that is either 'found' or 'made". If one disregards various complexities, basically all evidence needed for Internet or digital studies is already at hand. When interacting, searching, and listening to music at Spotify, for example, user data are constantly being produced. Such data are "documented in and of the system" and "with a little help from network administrators and service providers" it can be used as the empirical base for research (Bruhn Jensen 2011:52).

For researchers seeking to take empirical advantage of data flows at contemporary media platforms, it quickly becomes apparent "that such platforms do not present us with raw data, but rather with specially formatted information" (Marres \& Gerlitz 2015). Data, in short, are often biased. Twitter, for example, determines what data are available and how the data can be accessed, and researchers often have a hard time knowing what relevant data might be missing. Hence, the major academic problem confronting media scholars working with digital methods is the lack of access to data. In our project, the main difficulty in doing research on and around Spotify is the reluctance of the company to share data.

Consequently, user data must be acquired and compiled through other means such as by deploying bots as research informants or by recording and aggregating self-produced music and sounds. Building on the tradition of breaching ex- 
periments in ethnomethodology (Garfinkel 1967), where reactions are caused by disturbing or even violating commonly accepted rules or norms, our project has tried via repeated and modified so-called "interventions" to break into the hidden infrastructures of digital music distribution. On the one hand, we have been interested in broadly studying different data patterns and media processes at Spotify. On the other hand, we have also been keen on producing and obtaining research data, for example, by using bots as virtual listeners, by documenting (and tracing) Spotify's history through constantly changing interfaces, or by tracking and archiving advertisement flows. Using debugging software such as Fiddler or Ghostery, we have also tracked traffic between a computer and the Internet.

Although this thematic section of Culture Unbound is concerned with Spotify, basically any other streaming media services could be studied in similar ways. The various digital methods we present, use, and critically discuss can be used to analyse a range of different online services or platforms that today serve as key delivery mechanisms for works of culture, including YouTube, Netflix as well as various platforms for e-books or academic articles. Although our analysis is specific, the methods we propose are of more general relevance and concern. For example, using bots as research informants can be deployed for many different types of digital scholarship. Due to the transformation of media into data, digital methods can easily be used in research (albeit with some coding skills). When media at online services (such as Spotify) are coded and redefined as a purely data-driven communication form-with, on the one hand, content (e.g., media files and metadata) being aggregated through external intermediaries, and, on the other hand, user-generated data being extracted from listening habits-the singularity of the media experience is transformed and blended into what Jeremy Wade Morris has termed "a multimediated computing experience" (Wade Morris 2015: 191).

For a regular user, today's multimediated and exceedingly computational experience of online media takes on different and sometimes personalised forms. To understand the logic and rationale of contemporary media services and platforms, one should not shy away from but rather ask what exactly happens when data are turned into media and vice versa. What occurs and takes place beneath the black shiny surface of, say, the Spotify desktop client, with its green and greyish interface details and whited fonts and textures? It goes without saying, that research on the cultural implications of software-whether in the form of software studies, digital humanities, platform studies, or media archaeology-has repeatedly stressed the need for in-depth investigations on how computing technologies work combined with (more or less) meticulous descriptions of technical specificities (Kirschenbaum 2008, Chun 2011, Sterne, 2012, Ernst 2013). 


\section{Localising Spotify}

Departing from the interventionist and experimental approaches we have used in our research project, which both metaphorically and practically try to track and follow the transformation of audio files into streamed experiences in the simple way a postman would follow the route of a parcel from packaging to delivery, the notion of localisation has become salient. Following files is a technical impossibility in a streaming media context, yet approaching, encircling, and circumscribing Spotify, both as a company and a service, has also proven to be hard. In our research project, we have repeatedly asked insidiously simple questions: Where is Spotify? When is Spotify used? What is Spotify? It might seem naive, but during the research process it has become increasingly difficult for us to understand and grasp our object of study.

Asking Google the search question "What is a Spotify?" returns a snippet from Wikipedia: "Spotify is a music, podcast, and video streaming service, officially launched on 7 October 2008. It is developed by start-up Spotify AB in Stockholm, Sweden" (Wikipedia 2017). But such an answer hides more than it shows and can easily be problematized. Is Spotify, for example, a content platform, a distribution service, or a media company? Furthermore, music naturally lies at the heart of Spotify (even if podcasts and videos seem increasingly important), but what kind of content is accepted-i.e., how is music defined? And what about the Swedishness of Spotify? Where is the company located? Headquarters are still to be found in central Stockholm on Birger Jarlsgatan 61, but the service is now available in some 60 countries, not to mention the digital variety of desktop and mobile versions (which all differ slightly). In addition, how does one situate Spotify commercially and financially (i.e., how much money is Spotify making (or losing) and how can one measure its economic impact?

As is apparent from the four issues above-and one could easily have included yet another-localising Spotify is easier said than done. Starting, however, by determining whether Spotify is a tech or a media company, it was obvious that Spotify for several years foremost offered a technological solution for record companies struggling with piracy. In a private conversation in 2012, one of the authors of this introduction (Snickars) asked Sophia Bendz (at the time Head of Marketing at Spotify) what kind of company Spotify actually was. Without hesitating, Bendz stated that Spotify was a tech company, only distributing content produced by others. The tech identity, however, was somewhat dubious even in 2012 and has become increasingly harder to sustain. Advertisement serves an illustrative case in point. In endless discussions with record labels (around rights management), Spotify took the stance that the continuous offering of a zero-price version with recurrent advertisement (Spotify Free) would in the long run be the best solution, as this strategy would serve as an incentive to scale businesses and attract glo- 
bal listeners. Spotify's classification as strictly a tech company misses the fact that a core part of its business has been to provide content to audiences and selling those audiences to advertisers. Other music streaming services used a different strategy and Spotify has consequently struggled, and increasingly become more of a media company, all in order to keep to its business model with two versions of the product: the Free version (with embedded advertising) and the Premium version (without advertising).

Arguably, the music industry still sees Spotify as the top streaming service around, yet Spotify "has done little to address the lack of new music from a large collection of major artists when their albums are released" (Singleton 2016). That is, in a digital environment where streaming music becomes default, a focus on tech and distribution will only result in missed business opportunities. Indeed, Spotify has not really entered into content production (e.g., like Netflix), although some self-made videos are provided such as interviews with artists as well as other content (e.g., pop-ups that explain lyrics). Hence, stating that Spotify is only a tech company (in the form of a streaming service) fails to see other defining characteristics of the enterprise.

Secondly, "Music for everyone" is the company catch phrase, displayed, for example, when entering spotify.com. To localise Spotify, one might ask what kind of music does the service offer? In fact, one fundamental question we have struggled with in our research project is determining what sounds are perceived as music according to Spotify. It should be stressed that uploading music onto the service is outsourced to several so-called aggregation services. In short, these (and not Spotify) regulate content appearing on different music streaming platforms. In one of our interventions, we experimented with uploading self-produced music via different aggregators. These explorations with artificial sounds and music resulted in different responses. The same music (or sounds) passed some aggregators, but others did not define these "sounds" as music content at all. In short, rejection criteria of music aggregators turned out to be arbitrary. Hence, when principles as to what is considered music vary at the aggregation level, and consequently on streaming platforms such as Spotify, usually depending on whether users pay an aggregation fee or not, the line between music and non-music, artist and machine, becomes increasingly blurred.

A third way to use the notion of localisation to pinpoint Spotify is to look closer at geography and the hype around the "Swedishness" of Spotify. On the one hand, the company is still often associated with Sweden: "Swedish music-streaming service provider Spotify is in advanced talks to acquire German rival SoundCloud" (The Guardian, 2016). Yet, on the other hand, geographical localisation strategies also make it apparent that Spotify tries hard to transform itself into a global media company: "Spotify is tailoring its service for local tastes, from topical playlists to 
tiered pricing, as it prepares to expand its music streaming in Asia" (Bloomberg 2016). Spotify, in fact, increasingly acts as a global media company, and as a result, Patrick Vonderau (one of the researchers in our project) has recently claimed that "Spotify is neither particularly Swedish nor about music". While invocations of the company's Swedishness have been needed to sustain venture capital, and a "vision of 'European unicorns' ... to position Spotify at the sexy, cool end of digital innovation", Vonderau argues that in financial terms Spotify now acts more "as a digital broker whose history of equity rounds, market and debt capitalization, and board of directors firmly ties brokerage strategies to U.S.-based financial interests" (Vonderau 2017). Spotify, in short, operates increasingly like a traditional American media company.

A fourth way to try to frame and localise Spotify is to follow the money and look at the company's evasive finances. Some figures estimate that the company makes more than two billion dollars a year from subscription fees and advertising, yet approximately 80 percent of that income is (all likely) paid to record labels and artists. In general, the financial situation and status of Spotify remains concealed, yet the same basically goes for the commodity that is being sold. As Rasmus Fleischer argues in his article in this thematic section, a crucial issue when dealing with the political economy of digital media is understanding what kind of commodity is being sold and to whom.

Lately, it has even been claimed that Spotify is "causing a major problem for economists" (Edwards 2016). Within mainstream economics, it is now commonly acknowledged that GDP is just an empirical construct that is becoming ever more misleading (Coyle 2014, Economist 2016). One main problem is how to measure inflation: to establish a price index, it is necessary to quantify differences in quality between last year's products and this year's products. It is difficult to compare the price of music sold as discrete units and music bundled as a monthly subscription (Spotify Premium) or offered with advertisements (Spotify Free). Is it meaningful to calculate a hypothetical "price per track listened to" in any of these cases? And how should we measure, in monetary terms, the value of music recommendations? Because of such quandaries, economists like Erik Brynjolfsson and Andrew McAfee have pointed to Spotify as an example of how national accounts fail to capture the "consumer surplus" resulting from rapid technological progress (Brynjolfsson \& McAfee 2014: 174-189). Even a more traditional calculation of national accounts, which only includes those transactions where money is changing hands, poses delicate problems when locating Spotify. Thus, recent government inquiries from Sweden and the U.K. have singled out Spotify as the epitome of problems with measuring an economy increasingly built on digital services (Felländer 2015; Bean 2016). It seems that Spotify has not only disrupted the music and media industries but also has disrupted the ways in which the economic sta- 
tistics surrounding user data need to be measured and interpreted.

\section{Historicising Spotify}

The story of Spotify is commonly told as an extraordinary success story: over 100 million users and over $\$ 8$ billion valuation and growing. However, Spotify has yet to show a profit. So far, its losses have tended to grow faster than its turnover, so the survival of the service depends on ever larger injections of venture capital. This situation, typical for today's technology start-ups, tends to limit the opportunities for independent research. To attract investment and to secure deals with partner companies, it is necessary for Spotify to maintain a certain level of buzz in the news media, confirming the image of a company always expanding, always innovating, and always headed on a straight path towards a future monopoly position. No information will be let out if it does not play a predefined role in this public relations strategy.

One might argue that the buzz and hype, including problems in localising the company, makes it difficult for researchers to approach Spotify, at least compared to more established companies that have already gone public. Throughout most of Spotify's lifetime, there have been speculations about an imminent stock market launch, an IPO (Initial Public Offering), or a possible acquisition in which Spotify would be bought up by Google, Apple, or Facebook. Certain commentators have also questioned whether Spotify's business model is sustainable. These discussions and speculations have not lead anywhere and often remain obscure as vital details are kept secret via nondisclosure agreements between Spotify and the music industry. Another impossible (but lively) discussion has been concerned with whether Spotify is good for artists, as if artists exist as a homogenous group to which Spotify can be either good or bad.

From our research perspective, it is more relevant to ask how Spotify takes part in a redefinition of what it means to be a successful artist or a record company by changing the ways in which music is presented, commodified, and valuated. In other words, the producer of musical recordings cannot be thought of as existing independently of the distributor. As researchers, we must simply acknowledge that Spotify is a moving object and that the results from our digital experiments and interventions must be situated within a historical context (even though the company is not much older than ten years). One important source material for the historiography of Spotify, which has been essential for our research, is a major archive of news reports, including trade journals focusing on tech (e.g., Wired and Techcrunch), music (e.g., Billboard and Music Week) and advertising (e.g., Advertising Age and Marketing Week), all sources we have constantly been collecting.

Going through this archive, one is confronted by an immense level of buzz, 
speculations, rumours, and empty promises. Localising and historicising Spotify is in many ways a task of how one approaches this constant murmur. One possibility is to regard this buzz simply as a kind of noise that ought to be filtered out, leaving a smaller selection of verified stories, useful for producing a historiography over what Spotify has really done. We propose the opposite approach, however: Just as we follow the files using digital methods, we follow the buzz using archives (i.e., our historiography). This means working through a tremendous source material looking not only for what happened, but also after what Richard Barbrook has described as "the beta version of a science fiction dream: the imaginary future" (2007). The history of Spotify is, in fact, full of false predictions and visions. Taking these shortcomings into account provides an important corrective to the conventional narrative about the gradual realisation of a grandiose entrepreneurial vision.

It may surely be true that Spotify CEO, Daniel Ek, has a deep passion for music and that he enjoys playing the guitar, but when he and Martin Lorentzon founded Spotify in 2006, it was certainly not an attempt to disrupt the music industry to save it from piracy, as the official story now goes (Bertoni 2012) The original idea behind Spotify was purely technological: to create a platform for media distribution based on a peer-to-peer network. The first news reports in Sweden, in fact, presented Spotify as a company building a new infrastructure for film distribution. However, because video demanded too much bandwidth, Spotify's first set up and trials used music files as distribution content ( $\AA$ kesson 2007, Johansson 2015). To be more precise, the beta version of Spotify was loaded with pirated music files, downloaded by its employees through file-sharing services like The Pirate Bay (Andersson Schwarz 2013: 149). Music streaming proved attractive, and soon enough Ek and Lorentzon had conceived a business model for music, clearly inspired by the popularity of illicit file-sharing in Sweden. Spotify was to make music free but legal, available to consumers at no cost, while advertising provided all revenues.

Spotify's launch, thus, coincided perfectly with the broader hype around the idea that " $\$ 0.00$ Is the Future of Business" (Anderson 2008, Fleischer 2017), but also with the onset of a global financial crisis, which was soon to decimate the advertising market, making it hard to sustain ad-funded "free" services. The business of selling subscriptions for media services, however, tended to do remarkably well in the recession (Economist 2009). Spotify hence gradually changed its mind, now declaring that both advertising and subscriptions were to be equally important sides of their business model, while also dabbling with ideas of making money on sales of merchandise and concert tickets. In retrospect, it is striking how long the founders of Spotify resisted the idea of building a business fully dependent on subscription revenues. 


\section{Culture Unbound}

Historiography cannot do without an element of periodisation. With respect to Spotify's financial uncertainty and its dependence on venture capital, the company history can thus be understood over a timeline of investments. These have come in a series of funding rounds, from the first round (Series A) of about $\$ 20$ million to the most recent round of $\$ 1$ billion in convertible debt. Each time, the value of existing stocks has been diluted, the balance of ownership displaced in a new direction. The identity of the investors is usually public information, aggregated on websites like Crunchbase (2016), but the conditions detailed in each deal is always a secret. However, if one follows the buzz and maps it over the investment timeline, some of it becomes evident. Investments have, for example, been used mostly for international expansion (Series D, Series F) or for developing the streaming service in a specific direction (Series E).

Daniel Ek has been dubbed "the most important man in music" by Forbes (Bertoni 2012) and one of the ten most powerful people in the music industry (Billboard 2016), yet he is not in control of Spotify. The company's founders most certainly lost their majority share by 2009. In addition, Spotify's existence remains dependent on the willingness of the Big Three record labels (Universal Music Group, Sony Music Entertainment, and Warner Music Group) to renew their licensing deals. Hence there are several reasons why Spotify is not like Facebook: it is not profitable, it is not publicly traded, and it cannot dictate the terms in dealing with content providers. It would be silly to deny that Spotify is not dominant and mighty, but the power of Spotify is not easily located. Rather than being a single forceful actor trying to shape the future of music, Spotify indeed exists at the intersection of competing industries (tech, content, advertising, and finance).

One way to historicise Spotify in a more concrete manner is to look at altered strategies for music discovery. In the earlier period before its U.S. launch, Spotify's interface was centred around the search box (Fleischer 2015). Not much effort was put into assisting users who did not immediately know what music they wanted to hear. In other words, Spotify's ideal user was an individual with strong musical preferences (as part of his or her identity). When asked about the lack of social features in 2009, a Spotify director simply answered: "We're coming at it from the on-demand side" (Music Week 2009). This was also Spotify's real strength, according to influential magazines like Billboard and Wired; the service was considered fast, clean, and easy to use, and importantly so because it did not push music recommendations to its users (Bruno 2009, Peoples 2010, Pollack 2011).

This partly began to change in 2010-11, when Spotify established a strategic partnership with Facebook, following a Series C investment by Sean Parker (co-founder of Facebook and, before that, of Napster) who also joined Spotify's board of directors. The interface was gradually redesigned, moving away from the individualism of the search box and towards more social approaches of friction- 
less sharing: all music listening would be automatically shared with friends. This was met, however, by an outcry from many users, forcing Spotify to introduce new options for protecting the privacy of musical preferences (Spotify 2011a, Spotify 2011b, Financial Times 2011). In short, the social turn provided a new direction for Spotify's developers, moving away from the poverty of the empty search box and towards a third way, different from both algorithmic and expert-curated music recommendations (Fleischer 2017). By integrating with Facebook, Spotify hoped to create the ultimate discovery engine. Spotify's approach was to recommend music based on what the user's friends had put in their playlists. Friends, however, can have bad taste. Ultimately, social discovery turned out to be a failure in the light of Spotify's experience on the U.S. market. Spotify had emphasised the freedom to choose, but many Americans seemed to prefer the freedom from choice. By the end of 2012, Daniel Ek admitted that "Spotify is great when you know what music you want to listen to, but not so great when you don't" (Bercovici 2012).

Spotify's social turn was followed, just a couple of years later, by a curatorial turn. The development of this type of new music discovery approach (throughout 2013) was financed by a $\$ 100$ million investment round (series E) led by Goldman Sachs. Spotify was indeed not a vanguard in this movement. During 2012, industry observers began establishing as a fact that people love to simply lean back and listen. The future of streaming music was now more commonly sought in radio-like lean-back services such as Pandora, while the lean-forward approach of Spotify was seen as its Achilles' heel (Peoples 2012, Warren 2012). Trying to remedy this, Spotify first acquired Tunigo, a company specialised in building expert-curated music playlists. At the same time, Spotify discarded its old, individualist slogan: "Whatever you want, whenever you want it" (Spotify 2011c). New slogans were put in use: "Music for every moment" (Spotify 2013a) and "Soundtrack your life" (Spotify 2013b). In every country where Spotify was active, the local office began to recruit playlist curators with knowledge of local culture, but not specialised in any specific genres. The standard job description used was typical of Spotify's new approach: playlist curators should identify "songs to fit different situations" and create "playlist listening experiences for a multitude of moods, moments, and genres" (Spotify 2014). Here, it seems that Spotify had opted for a more human approach of expert curation, but Spotify was simultaneously working on algorithmic recommendation systems in close cooperation with the music intelligence company The Echo Nest, which it acquired in 2014. Neither a purely human nor a purely algorithmic curation system would be conceivable, but a combination of the two could work. In any case, it is finally interesting to note how this dichotomy was reinforced in 2015 by Apple when it presented its new streaming music service. Apple Music was then framed as the more warm and human alternative to the allegedly cold and all-too-algorithmic Spotify (Apple 2015, Dredge 2015). 


\section{About the Articles}

As is evident from the discussions above, analysing Spotify is not an easy task. If localising Spotify is hard, historicizing the company's whereabouts doesn't result in a particularly straight trajectory either. On the contrary, users, competitors, and investors have all influenced the different directions that Spotify has taken and will all likely continue to do so. Hence, if music discovery today is important for Spotify to both satisfy and create a desire to consume and listen to more music, discovering Spotify is another matter. This thematic section of Culture Unbound, however, tries to locate the streaming service from several different perspectives. It brings together ongoing and differentiated research within the project "Streaming Heritage: Following Files in Digital Music Distribution". The four articles presented are, in short, all concerned with uncovering and finding out more about Spotify via different research strategies and methods. Three of the articles use digital methods in their approach, trying to get closer to Spotify through inventive experiments. Two of the longer articles (Eriksson \& Johansson and Snickars) also explicitly use bots as research informants. A bot is a small software application that runs automated tasks (or scripts), and within interventions at Humlab we have repeatedly used massive set-ups of bots, sometimes working with up to 500 virtual listeners.

In the first article in the thematic section, "If the song has no price, is it still a commodity?", Rasmus Fleischer reviews some of the recent literature on how music is marketed. Over the last century, music has been subject to different regimes of commodification, sold as a published score, as a live performance, or as recorded sound. Streaming services like Spotify, however, represent a different commodification regime, Fleischer argues. Therefore, it is necessary to identify and define the commodity Spotify sells. Fleischer criticises prevalent conceptions of the digital music commodity that often assume that each song (whether downloaded or streamed) is a commodity, which is indeed correct in the case of downloading services like the iTunes Store. But the user of Spotify will (currently) never see a price tag on a song. In fact, Spotify is not selling discrete pieces of recorded sound and is not offering consumers millions of commodities; Spotify offer only one commodity: the subscription. This product is a bundle that includes not only access to all songs in the catalogue, but also the maintenance of a personalised profile connected to a variety of playlists tailored for pre-defined activities. Music is still commodified by Spotify, Fleischer argues, but as a commodity, music can mean different things. Spotify is, for example, buying music through various aggregation services in the form av copyright licenses, bundling it, adding new features, and then selling music as a personalised experience. When analysing commodification, it is always necessary to ask what kind of object is the commodity. 
In their article, "Tracking Gendered Streams", Maria Eriksson and Anna Johansson investigate whether music recommendations at Spotify are gendered. As is well known, one of the most prominent features on contemporary music services is the provision of personalised music recommendations that come about through the profiling of users and audiences. Based on a range of bot experiments, their article explores patterns in music recommendations provided by Spotify in its Discover feature. The article specifically focuses on issues around gender and explores whether the Spotify client and its music recommendation algorithms are performative of gendered user identities and taste constellations. Exploring the tension between gendered publics and Spotify's promise to deliver personalised music recommendations to everyone, Eriksson and Johansson's research ties into broader questions about the workings and effects of algorithmic knowledge production. They argue that issues around gender are important in this context, since Spotify's music recommendations can be considered as one of the venues where gendered norms and ideals are reproduced and manifested. Eriksson and Johansson's results for example reveal that male artists were highly overrepresented in Spotify's music recommendations; an issue which they argue prompts users to reproduce hegemonic masculine norms within the music industries. Although the results should be approached as highly historically and contextually contingent, Eriksson and Johansson argue that they do give some evidence of the ways in which gender becomes tied to issues of taste and identity formation in algorithmic knowledge-making processes.

In his article, "More of the Same - On Spotify Radio", Pelle Snickars takes a similar approach as Eriksson and Johansson, working extensively with bots as research informants. Snickars main interest is the so-called radio function at streaming services, and Spotify Radio in particular. It is a service that "lets you sit back and listen to music you love. The more you personalise the stations to match your tastes the better they get", at least according to the company slogan. Basically, the radio functionality allows users (via various unknown algorithms) to find new music within Spotify's vast back-catalogue, offering a potential infinite avenue of discovery. Nevertheless, the radio service has also been disliked and blamed for playing the same artists over and over. Together with the Humlab programmers, Snickars set up an experiment to explore the possible limitations and restrains found within "infinite archives" of music streaming services. The hypothesis was that the radio function of Spotify does not consist of an infinite series of songs although it may appear so to the listener; it is actually a finite loop. Spotify Radio claims to be personalised and never-ending, yet music seems to be delivered in limited loop patterns. What would such loop patterns look like? The intervention used 160 bot listeners programmed to listen to different Swedish music from the 1970s. Snickars is not primarily interested in personalised recommendations, 
but rather how Spotify Radio functions generically. The first (and major) round of bots started Spotify Radio based on the highly popular Abba song "Dancing Queen" (with some 65 million streams). The second (and minor) round of bots used the less well-known Swedish progressive rock band Råg i Ryggen's "Queen of Darkness" (with some 10,000 streams). Snickars article describes different research strategies when dealing with proprietary data as well as the background and the establishment of the radio functionality at streaming services like Spotify. Essentially, his article empirically recounts, discusses, and analyses the radio looping interventions set up at Humlab.

Finally, in their co-written article, "Studying Ad Targeting with Digital Methods: The Case of Spotify", Patrick Vonderau and Roger Mähler provide a brief description of digital methods used in studying digital advertising technologies. To study ad targeting, researchers have an inventory of tested methods at their disposal but a problem of access to verifiable data persists. In order to understand which types of key stakeholders are involved in ad targeting processes, the authors experimented with digital tools to complement data collection. In doing so, they followed the well-established idea of taking up methods that are already embedded in digital infrastructures and practices.

This thematic section of Culture Unbound goes under the hood of Spotify and looks critically at its tech stack. It is important to remember that Spotify's data infrastructure resembles other services. The analyses put forth in the different articles (sometimes) approximates media specific readings of the computational base; that is, the mathematical structures underlying various interfaces and surfaces resonate with media scholarly interests in technically rigorous ways of understanding the operations of material technologies. Then again, it is also important to stress that the Spotify infrastructure is hardly a uniform platform. Rather it is downright traversed by unseen data flows, file transfers, and information retrieval in all kinds of directions, be they metadata traffic identifying music, aggregation of audio content, playout of streaming audio formats (in different quality ratings), programmatic advertising (modelled on finance's stock exchanges), or interactions with other services (notably social media platforms). This thematic section tries to uncover and make visible some of these streams.

Rasmus Fleischer is a postdoctoral researcher based at the Department of Economic History, Stockholm University. His research interests are located in the intersections between culture and economy, as well as technology and politics. Most of all, he has explored 20th century media history, transformations of copyright and the commodification of music. E-mail: rasmus.fleischer@ ekohist.su.se 
Pelle Snickars is Professor of Media and Communication Studies, specialising in digital humanities at Umeå university and is affiliated with the Humlab research centre. His research focuses on the relationship between old and new media, media economy, digitisation of cultural heritage, media history as well as the importance of new technical infrastructures for the humanities. E-mail: pelle.snickars@ umu.se

\section{Notes}

${ }^{i}$ Some of the digital methods used in this thematic section are non-compliant with Spotify's Terms of Service (ToS). The data collection has ended and did not involve any user data. With the public and academic interest in mind, we appreciate Spotify's forbearance with any trespassings of ToS that our data collection involved.

ii The research project, "Streaming Heritage. Following Files in Digital Music Distribution" involves system developers Roger Mähler and Johan von Boer (at Humlab, Umeå University), as well as researchers Pelle Snickars, Maria Eriksson, Anna Johansson (at Umeå University), Rasmus Fleischer (at Stockholm and Umeå University), and Patrick Vonderau (at Stockholm University). For more information: http://streamingheritage.se/.

\section{References}

Åkesson, Nils (2007): “De kan tjäna 900 miljoner”, Dagens Industri, January 16.

Allen Anderson, Paul (2015): "Neo-Muzak and the Business of Mood" Critical Inquiry 41(4), 811-840.

Andersson Schwarz, Jonas (2013): Online File Sharing: Innovations in Media Consumption, London: Routledge.

Apple (2015): Video recording from June event 2015, June 8. http://www.apple.com/ live/2015-june-event/

Barbrook, Richard (2007): Imaginary futures: from thinking machines to the global village, London: Pluto.

Bean, Charles (2016): "Independent review of UK economic statistics", HM Treasury Report https://www.gov.uk/government/publications/independent-review-of-uk-economic-statistics-final-report (Accessed 15/03/17)

Bercovici, Jeff (2012): "Spotify Adds Features, Taking a Page From, Yes, Myspace", Forbes, December 6.

Bertoni, Steven (2012): "Spotify’s Daniel Ek: The Most Important Man In Music", Forbes January 4. http://www.forbes.com/sites/stevenbertoni/2012/01/04/spotifysdaniel-ek-the-most-important-man-in-music/\#5d77b2520263 (Accessed 15/03/17)

Billboard (2016): "Billboard's 2016 Power 100 List Revealed", Billboard, February 12. http://www.billboard.com/articles/business/6874816/billboards-2016-power100-list-revead (Accessed 15/03/17)

Bloomberg (2016): "Spotify focuses on localisation to smooth next expansion in Asia", July 20. http://www.businesstimes.com.sg/consumer/spotify-focuses-on-localisa- 


\section{Culture Unbound}

Journal of Current Cultural Research

tion-to-smooth-next-expansion-in-asia (Accessed 15/03/17)

Bruno, Antony (2009): "See Spotify run", Billboard, 121(25), p. 11

Bruhn Jensen, Klaus (2011): "New Media, Old Methods-Internet Methodologies and the Online/Offline Divide", Mia Consalvo \& Charles Ess (eds): The Handbook of Internet Studies, London: Blackwell.

Brynjolfsson, Erik \& Andrew McAfee (2014): The second machine age: work, progress, and prosperity in a time of brilliant technologies, New York: W. W. Norton \& Company.

Chun, Wendy (2011): Programmed Visions: Software and Memory, Cambridge, Mass: MIT Press.

Coyle, Diane (2014): GDP: a brief but affectionate history, Princeton: Princeton University Press.

Crunchbase (2016): "Spotify". https://www.crunchbase.com/organization/spotify

Dredge, Stuart (2015): "Apple Music interview: 'Algorithms can’t do it alone - you need a human touch", The Guardian, June 9.

Economist (2009): "The triumph of the monthly bill", The Economist, October 8.

Economist (2016): “The trouble with GDP”, The Economist, April 30.

Edwards, Jim (2016): "Spotify is causing a major problem for economists", Business Insider, September $26 \mathrm{http://www.businessinsider.de/spotify-problem-for-econo-}$ mists-2016-9 (Accessed 15/03/17)

Ernst, Wolfgang (2013): Digital Media and the Archive, Minneapolis: University of Minnesota Press.

Felländer, Anna (2015): “The opportunities and challenges of digitalisation”, Digital Opportunities, Report from the Digitalisation Commission (SOU 2015:65).

Financial Times (2011): "Spotify bows to privacy pressure as Facebook sharing meets friction", blog post, September 29. http://blogs.ft.com/tech-blog/2011/09/spotify-private-listening/ (Accessed 15/03/17)

Fleischer, Rasmus (2015): "Towards a Postdigital Sensibility: How to get Moved by too Much Music", Culture Unbound 7, 255-269.

Fleischer, Rasmus (forthcoming, 2017): "Nätutopier och nätdystopier. Om 2000-talets sökande efter internets väsen", Anders Burman \& Lena Lennerhed (eds): Samtider, Göteborg: Daidalos.

Galuszka, Patryk (2015): "Music Aggregators and Intermediation of the Digital Music Market", International Journal of Communication 9, 254-273.

Garfinkel, Harold (1967): Studies in Ethnomethodology, Englewood Cliffs: Prentice Hall.

Guardian (2016): "Spotify in advanced talks to buy SoundCloud, reports say", 28 September. https://www.theguardian.com/technology/2016/sep/28/spotify-soundcloud-acquisition-reports (Accessed 15/03/17)

Johansson, Sara (2015): "Så startade Spotify", Centre for Business History, February 2 http://naringslivshistoria.se/bizstories-nyheter/naringslivshistoria/en-bra-ide-arbara-borjan/ (Accessed 15/03/17)

Kirschenbaum, Matthew (2008): Mechanisms. New Media and the Forensic Imagination, Cambridge, Mass: MIT Press.

Marres, Noortje \& Gerlitz, Carolin (2016): "Interface methods: renegotiating relations between digital social research, STS and sociology", The Sociological Review 64, 21-46.

Morozov, Evgeny (2013): To Save Everything, Click Here: The Folly of Technological Solutionism, New York: Public Affairs.

Music Week (2009): "What does the future hold for Spotify?", Music Week 36, 15.

Peoples, Glenn (2010): "Is Spotify really all that?", Billboard, 122(44), 20-21.

Peoples, Glenn (2012): "Internet Radio: The Next Digital Underground", Billboard, July 20. http://www.billboard.com/biz/articles/news/1084561/internet-radio-the-next-digital-underground (Accessed 15/03/17)

Pollack, Neal (2011): “The Celestial Jukebox", Wired 19(1), 74. 
Rogers, Richard (2013): Digital Methods, Cambridge, Mass.: MIT Press.

Ruppert, Evelyn, Law, John \& Savage, Mike (2013): "Reassembling social science methods: the challenge", Theory, Culture \& Society 30(4), 22-46.

Singleton, Micah (2016): “Does Spotify need to go after exclusive content?" February 18. http://www.theverge.com/2016/2/18/11054460/spotify-exclusive-content-apple-tidal (Accessed 15/03/17)

Spotify (2011a): "Spotify introduces music to your social life", blog post, September 21. https://news.spotify.com/se/2011/09/21/spotify-and-facebook/(Accessed $15 / 03 / 17)$

Spotify (2011b): "What you share and how to control it", blog post, September 27. https://news.spotify.com/se/2011/09/27/what-to-share/ (Accessed 15/03/17)

Spotify (2011c): "What is Spotify?", archived version, July 14. https://web.archive.org/web/20110714070521/http://www.spotify.com/int/about/what/ (Accessed $15 / 03 / 17)$

Spotify (2013a): Main US website, archived version, August 6. https://web.archive. org/web/20130806170904/https:/www.spotify.com/us/video-splash/?utm sour$\underline{\text { ce}=\text { spotify\&utm medium=web\&utm campaign=start }}($ Accessed 15/03/17)

Spotify (2013b): Main US website, archived version, May 2. https://web.archive.org/ web/20130502232221/https:/www.spotify.com/us/ (Accessed 15/03/17)

Spotify (2014): "Career Opportunities", archived version, January 22. https://web. archive.org/web/20141221063949/https://www.spotify.com/se/jobs/opportunitis (Accessed 15/03/17)

Sterne, Jonathan (2012): MP3: The Making of a Format, Durham: Duke University Press, 2012

Vonderau, Patrick (forthcoming 2017): "Scaling Up: Streaming Services, High Finance, and Advertising Technology", Denise Mann (ed): Content Wars, New Brunswick: Rutgers University Press.

Wade Morris, Jeremy (2015): Selling Digital Music, Formatting Culture, Oakland: University of California Press.

Warren, Christina (2012): "Spotify Wants to Make Music Discovery Truly Social", Mashable, December 6. http://mashable.com/2012/12/06/spotify-social-discovery/ (Accessed 15/03/17)

Wikipedia (2017): "Spotify" https://en.wikipedia.org/wiki/Spotify (Accessed $15 / 03 / 17)$

Wikström, Patrik (2013): The Music Industry, Cambridge: Polity Press.

Wikström, Patrik \& DeFilippi, Robert (eds) (2016): Business Innovation and Disruption in the Music Industry, Cheltenham: Elgar. 